\title{
Nalbuphine versus Dexmedetomidine as an Analgesic Additive to Lidocaine in Intravenous Regional Anesthesia IVRA
}

\author{
Mohamed Elramely ${ }^{*}$, Hatem Elmoutaz ${ }^{2}$ \\ ${ }^{1}$ National Cancer Institute, Cairo University, Giza, Egypt \\ ${ }^{2}$ Beni-Suef University, Beni-Suef, Egypt \\ Email: *mramely@hotmail.com
}

Received 4 April 2016; accepted 25 July 2016; published 28 July 2016

Copyright (C) 2016 by authors and Scientific Research Publishing Inc.

This work is licensed under the Creative Commons Attribution International License (CC BY).

http://creativecommons.org/licenses/by/4.0/

(c) (i) Open Access

\section{Abstract}

Intravenous Regional Anesthesia (IVRA) is easy to administer and reliable. But delayed onset and lack of postoperative analgesia are the major limitations. Accordingly, many additives have been tried. Dexmedetomidine is a highly selective $\alpha$-2 adrenoceptor agonist. Addition of dexmedetomidine to lignocaine is effective in decreasing the anesthetic requirements and prolonging the analgesic duration. On the other hand, many theories explain that opioids may exert their peripheral action through peripheral opioid receptors. The aim of the study was to compare the analgesic efficacy of nalbuphine and dexmedetomidine when used separately as adjuvants to lidocaine during IVRA with the effect of lidocaine alone. Sixty adult patients, who were scheduled for surgery of the hand or the forearm under intravenous regional anesthesia, were included in this study. The patients were randomly allocated into three equal groups. The syringes in all groups contained 3 $\mathrm{mg} / \mathrm{kg}$ of lidocaine $0.5 \%$ diluted in $40 \mathrm{ml}$ isotonic saline. Group C: Control group. Group D: Dexmedetomidine group, $1 \mathrm{mic} / \mathrm{kg}$ dexmedetomidine diluted was added. Group N: Nalbuphine group, $20 \mathrm{mg}$ nalbuphine was added. Sensory onset time $(\mathrm{min})$ as well as motor block onset time (min) were significantly shorter in Groups $N(2.0 \pm 1.7)(3.8 \pm 2.1)$ respectively, and $D(2.2 \pm 1.8)(4.6 \pm$ $2.2)$ respectively compared to Group $C(3.6 \pm 1.6)(7.1 \pm 1.4)(P<0.05)$, with no significant differences between nalbuphine and dexmedetomidine groups. Sensory and motor block recovery times (min) were significantly longer in Groups $N(9.6 \pm 0.7)(10.3 \pm 1.2)$ and $D(8.1 \pm 1.1)(9.1 \pm$ 2.1) when compared to Group $C(3.4 \pm 2.1)(3.7 \pm 3.1)(P<0.05)$, without significant differences between nalbuphine and dexmedetomidine. Ramsay sedation score was significantly higher $(\mathrm{RSS}=2)$ in 14 patients (70\%) in Group D compared to Groups $C$ and $N$ during the first 30 min after the release of tourniquet.

\footnotetext{
${ }^{*}$ Corresponding author.
} 


\section{Keywords}

\section{Nalbuphine, Dexmedetomidine, IVRA}

\section{Introduction}

Intravenous Regional Anesthesia (IVRA) was first used by August Bier in 1908. This technique is easy to administer, reliable and cost-effective for short surgical procedures of the extremities performed on an ambulatory basis [1] with success rate of approximately 95\% - 100\% [2]. Lidocaine becomes the local anesthetic of choice for Intravenous Regional Anesthesia (IVRA) because of the lack of cardiac toxicity and neurotoxicity. But, delayed onset of action, poor muscle relaxation and lack of postoperative analgesia are the major limitations of this technique. Accordingly, many additives have been tried to overcome this problem. Muscle relaxants, ketamine, ketorolac, clonidine and opioids are examples of these adjuvants, and their effects have been studied in detail [3].

Dexmedetomidine is a highly selective $\alpha$-2 adrenoceptor agonist. It has sympatholytic, sedative, amnestic, and analgesic properties. It provides a unique analgesia, without respiratory depression best described as opioidsparing. The analgesic properties of $\alpha$-2-agonists are mediated by Supraspinal (locus ceruleus) and spinal (dorsal horn) mechanisms. Moreover, it decreases sympathetic outflow through a central action in a dose-dependent manner, these presynaptic sites of action are clinically significant because they modulate the release of norepinephrine. This inhibitory effect on neurotransmitter release is mediated by the blockage of calcium entry into nerve terminals. Addition of dexmedetomidine to lignocaine in Bier's block is proved to be effective in decreasing the anesthetic requirements and prolonging the analgesic duration [4].

On the other hand, many theories explain that opioids may exert their peripheral action through peripheral opioid receptors. They may also have their own local anesthetic effect by blocking sodium channels at the peripheral nerve endings [5]. Nalbuphine is a mixed k-agonist- $\mu$-antagonist opioid of the phenanthrene series. It is chemically related to naloxone and oxymorphone. It activates the spinal and supraspinal opioid receptors leading to adequate analgesia with cardiovascular stability, minimal sedation, less respiratory depression, less physical dependence, as well as less nausea and vomiting. All these advantages are due to lack of the agonist effect on $\mu$-receptors [6].

The aim of the study was to compare the anesthetic and analgesic efficacy of nalbuphine and dexmedetomidine when used separately as adjuvants to lidocaine during IVRA (Bier's block) with the effect of lidocaine alone.

\section{Patient and Methods}

This study was conducted at National Cancer Institute, Cairo University from July 2014 to September 2015, after approval of local ethical committee \& obtaining informed consent from all patients. Sixty adult patients of ASA physical status I and II, aged 20 - 60 years, who were scheduled for surgery of the hand or the forearm under intravenous regional anesthesia, were included in this study. Patients with Raynaud's disease, history of drug allergy, sickle cell anemia, Liver diseases and kidney diseases were excluded from the study. The patients were randomly allocated into three equal groups using computer-based lists and then covered in closed envelopes. The syringes in all groups contained $3 \mathrm{mg} / \mathrm{kg}$ of lidocaine (2\% Lidocaine, Rotexmedica, Trittan, Germany). Group C: Control group, 20 patients received $3 \mathrm{mg} / \mathrm{kg}$ lidocaine $0.5 \%$ diluted in $40 \mathrm{ml}$ isotonic saline. Group D: Dexmedetomidine group, 20 patients received $3 \mathrm{mg} / \mathrm{kg}$ lidocaine $0.5 \%$ and $1 \mathrm{mic} / \mathrm{kg}$ dexmedetomidine diluted in $40 \mathrm{ml}$ isotonic saline. Group N: Nalbuphine group, 20 patients received $3 \mathrm{mg} / \mathrm{kg}$ lidocaine $0.5 \%$ and $20 \mathrm{mg}$ nalbuphine diluted in $40 \mathrm{ml}$ isotonic saline.

Patients were premedicated with IV $0.05 \mathrm{mg} / \mathrm{Kg}$ of midazolam. After the patient had been taken to the operating room, mean arterial blood pressure (MAP), peripheral oxygen saturation $\left(\mathrm{SPO}_{2}\right)$ and heart rate (HR) were monitored. Two cannulas were placed, one 22-gauge intravenous (IV) cannula in the dorsum of the hand of the surgical extremity and a second 20-gauge IV cannula in the non-operative arm for crystalloid infusion. The operative arm was elevated for 2 min then exsanguinated with an esmarch bandage. A pneumatic double tourniquet was placed a round upper arm, and the proximal cuff was inflated to $250 \mathrm{mmHg}$. Circulatory isolation of the arm was verified by inspection, absence of radial pulse, and loss of pulse oximetry tracing in the epsilateral 
index finger. After the bandage was removed, $40 \mathrm{ml}$ of the respective solutions were injected over 20 seconds by an anesthesiologist. The Sensory block was assessed by pinprick performed with a 22-gauge needle every 30 seconds until the dermatomal sensory block of medial and antebrachial cutaneous, ulnar, median and radial nerves achieved. Motor function was assessed by asking the patients to flex and extend his/her wrist and fingers and complete motor block was noted when no voluntary movement was possible. Sensory block onset time was noted as the time elapsed from drug injection to complete sensory block achieved in all dermatomes. Motor block onset time was the time elapsed from injection of study drug to complete motor block. After complete sensory and motor blocks were achieved, the distal tourniquet was inflated to $250 \mathrm{mmHg}$, and the proximal tourniquet was released and the surgery was started. MAP, $\mathrm{HR}$ and $\mathrm{SPO}_{2}$ level were recorded before application of tourniquet and after the application of tourniquet every five minute and were measured after release of the tourniquet, and postoperatively at $30 \mathrm{~min}, 1 \mathrm{hr}, 2 \mathrm{hr}, 3 \mathrm{hr}, 4 \mathrm{hr}, 6 \mathrm{hr}$ and 24 hours. Pain due to the tourniquet was assessed with visual analogue scale (VAS) scores [7] $(0=$ no pain and $10=$ worst pain imaginable). Levels of sedation were assesses with the Ramsey sedation scale [8] as follows: 1-patient is anxious and agitated or restless or both, 2-patients is cooperative, oriented and tranquil, 3-patient responds to command only, 4-patient exhibits brisk response to light glabellar tap or loud auditory stimulus, 5-patient exhibits a sluggish response to light glabellar tap or loud auditory stimulus, and 6-patients exhibits no response [8].

Both VAS and sedation levels were recorded before and after the application of tourniquet and during the operation $(10,15,20,30,40,50$ and $60 \mathrm{~min})$. When pain due to tourniquet was $>3$ on the VAS, patients were given nalbuphine $5 \mathrm{mg}$ intravenously increments up to $0.1 \mathrm{mg} / \mathrm{kg}$ and total administered dose were noted. Oxygen was administered with face mask if $\mathrm{SPO}_{2}$ was lower than $91 \%$. At the end of the operation patients were asked to qualify the operative conditions such as tourniquet pain or incisional pain.

The tourniquet was not deflated before 30 min and was not inflated more than 1.5 hours. At the end of the operation, the tourniquet deflation was performed by cyclic deflation technique (the tourniquet was deflated three times in a cyclic manner with 10 seconds period of deflation). Sensory recovery time was noted (time elapsed after tourniquet deflation up to recovery of pain in all innervated areas determined by pinprick test). Motor block recovery time was noted (the time elapsed after tourniquet deflation up to movement of fingers). Also, first analgesic requirement time was noted (the time elapsed after tourniquet release to the first patient request of analgesic). In the postoperative period if patients started to complain (VAS $>3$ ); rescue analgesia was given in the form of paracetamol (Perfalgan ${ }^{\circledR}$ ) 1gm IV drip and/or diclofenac sodium (Voltaren ${ }^{\circledR}$ ) $75 \mathrm{mg}$ IM, and/or nalbuphine $5 \mathrm{mg}$ IV (with maximum daily dose of $2 \mathrm{mg} / \mathrm{Kg} /$ day) till VAS $\leq 3$. And total amount of nalbuphine administered in first 24 hours to each group were recorded.

During the first 2 hours in the post-anesthetic care unit and later in the surgical ward, patients were questioned for circumoral numbness and tingling, nausea and vomiting, skin rash, tinnitus, gastric discomfort and other side effects were noted if encountered and MAP, HR and VAS scores were assed every 2 hours postoperatively during the first 24 hours.

The primary outcome of this study was the time to first analgesic request. The onset, duration times of both sensory and motor blocks, and complications related to the use of the drugs or technique were considered as Secondary outcome.

\section{Statistical Methods}

The primary outcome variable was postoperative analgesia, assuming that the mean duration of the sensory block of lidocaine is 2 hours, two-tailed $\alpha$ error probability of 0.05 and $\beta$ error probability of 0.2 (power of $85 \%$ ); a total sample size of 60 patients, randomly allocated into three equal groups (20 patients each), will be required to detect a presumed minimum clinically significant difference of $10 \%$ in the duration of sensory block. Statistical power calculations was performed using computer program G*Power 3 for Windows (Franz Faul, Universität Kiel, Germany).

Collected data was presented as mean $( \pm \mathrm{SD})$, numbers and percentages, as appropriate. Categorical variables were analyzed using Chi-square $\left(\chi^{2}\right)$. Continuous variables were analyzed using unpaired Student's t-test or univariate two-group repeated measures "mixed-design" analysis of variance (ANOVA) with post-hoc Dunnett's test as appropriate. Nominal and non-normally distributed variables were analyzed using Mann-Whitney U test. Statistical analysis was performed using the computer program SPSS (Statistical Package for Social Sciences), Version 20, 2011. P value $<0.05$ was considered statistically significant. 


\section{Results}

There were no significant differences among groups for demograghic data and total tourniquet time (Table 1).

Sensory onset time (min) as well as motor block onset time (min) were significantly shorter in Groups N, and D compared to Group C, with no significant differences between nalbuphine and dexmedetomidine groups. Sensory recovery time ( $\mathrm{min}$ ) and motor block recovery time (min) were significantly longer in Groups N and D when compared to Group C. But no significant differences between nalbuphine and dexmedetomidine (Table 2).

Tourniquet pain onset time was non-significant between three groups. The numbers of patients who required nalbuphine only 1 in Group C, and none in Groups N and D (Table 2). Postoperative VAS score in Groups N and D compared to Group C were significantly lower, while it was comparable between both groups (N and D). Time to first dose of supplementary analgesia was significantly longer in Groups N and D compared to Group C, and also there was significant differences between nalbuphine and dexmedetomidine groups. The postoperative analgesic consumption in the first $24 \mathrm{~h}$ was significantly lower in Group N and Group D than Group C, and also there was significant differences between naluphine and dexmedetomidine groups (Table 3). As shown in Table 4, 6 patients (30\%) developed bradycardia just after tourniquet deflation in Group D compared to no patients (0\%) in Groups $\mathrm{N}$ and $\mathrm{C}$. This decrease in heart rate was accompanied by insignificant decrease in blood pressure and all of them responded to $1 \mathrm{mg}$ IV atropine (although patients in Group D recorded lower levels of blood pressure after tourniquet deflation, the results were statistically insignificant when compared to those recorded in Groups C and N). Ramsay sedation score was significantly higher (RSS $=2$ ) in 14 patients (70\%) in Group D

Table 1. Demographic data, and time of tourniquet pain.

\begin{tabular}{ccc}
\hline & Group C $(n=20)$ & Group N $(n=20)$ \\
Age (years) & $35.0 \pm 14.0$ & $34.6 \pm 14.3$ \\
Gender (M/F) & $15 / 5$ & $14 / 6$ \\
Weight (kg) & $74.2 \pm 5.9$ & $75.6 \pm 4.1$ \\
Surgical duration (min) & $50.8 \pm 16.01$ & $43.9 \pm 21.9$ \\
Time of tourniquet application (min) & $60.4 \pm 13.9$ & $58.4 \pm 13.9$ \\
\hline
\end{tabular}

Data were expressed as mean $( \pm \mathrm{SD})$ number.

Table 2. Performance of intra-operative anesthesia of different agents used in the study.

\begin{tabular}{|c|c|c|c|c|}
\hline & Group C $(n=20)$ & Group N $(n=20)$ & Group D $(n=20)$ & $\mathrm{P}$ value \\
\hline Onset of sensory block (min) & $3.6 \pm 1.6$ & $2.0 \pm 1.7^{*}$ & $2.2 \pm 1.8^{*}$ & $<0.05$ \\
\hline Recovery time of sensory block (min) & $3.4 \pm 2.1$ & $9.6 \pm 0.7^{*}$ & $8.1 \pm 1.1^{*}$ & $<0.05$ \\
\hline Onset of motor block (min) & $7.1 \pm 1.4$ & $3.8 \pm 2.1^{*}$ & $4.6 \pm 2.2^{*}$ & $<0.05$ \\
\hline Recovery time of motor block (min) & $3.7 \pm 3.1$ & $10.3 \pm 1.2^{*}$ & $9.1 \pm 2.1^{*}$ & $<0.05$ \\
\hline $\begin{array}{l}\text { Number of patients who needed analgesia } \\
\text { intra operative (VAS }>3 \text { ) }\end{array}$ & 1 & 0 & 0 & \\
\hline
\end{tabular}

${ }^{*} \mathrm{P}$ value less than 0.05 is considered statistically significant. Data are presented as mean $\pm \mathrm{SD}$.

Table 3. Performance of postoperative analgesia of different agents used in the study.

\begin{tabular}{cccc}
\hline & Group C $(n=20)$ & Group N $(n=20)$ & Group D (n=20) \\
\hline $\begin{array}{c}\text { Postoperative VAS scores } \\
\text { Time to first dose of postoperative supplementary } \\
\text { analgesia (Paracetamol) (min) }\end{array}$ & $3.9 \pm 2.6$ & $1.8 \pm 1.3^{*}$ & $2.2 \pm 1.7^{*}$ \\
$\begin{array}{c}\text { Total dose of consumption of nalbuphine (mg) in } \\
\text { the first 24 h }\end{array}$ & $34.75 \pm 5.05$ & $18.5 \pm 4.32^{*}$ & $212.4 \pm 9.6^{*}$ \\
\hline
\end{tabular}

${ }^{*} \mathrm{P}$ value less than 0.05 is considered statistically significant. Data are presented as mean $\pm \mathrm{SD}$. 
Table 4. Incidence of complications between the three groups.

\begin{tabular}{cccc}
\hline & Group C $(n=20)$ & Group N $(n=20)$ & Group D (n=20) \\
\hline $\begin{array}{c}\text { Bradycardia just after tourniquet deflation } \\
\begin{array}{c}\text { Ramsay sedation score of [RSS = 2] during } \\
\text { the first 30 min }\end{array}\end{array}$ & 0 & 0 & $7(35 \%)^{*}$ \\
\hline
\end{tabular}

Data were expressed as number or percent.

compared to Groups $\mathrm{C}$ and $\mathrm{N}$ during the first $30 \mathrm{~min}$ after the release of tourniquet. There were no side effects noticed during the study related to systemic absorption of local anesthesia such as circumoral numbness and tingling, convulsion, respiratory depression and hemodynamic instability and also there were no side effects noticed related to tourniquet such as nerve palsy.

\section{Discussion}

This study showed that the sensory as well as motor block onset times were significantly shorter in Groups $\mathrm{N}$ and D, Sensory and motor block recovery times were significantly longer in Groups N and D (Table 2). Postoperative VAS score in Groups N (1.8 \pm 1.3$)$ and D (2.2 \pm 1.7$)$ compared to Group C (3.9 \pm 2.6$)$ were significantly lower $(\mathrm{P}<0.001)$. Time to first dose of supplementary analgesia was significantly longer in Groups $\mathrm{N}$ $(271.9 \pm 9.1)(\mathrm{P}<0.0001)$. The postoperative analgesic consumption in the first $24 \mathrm{~h}$ was significantly lower in Group N (Table 3).

Our results goes with Memis, D, Esmaoglu A, and Kanazi GE as they concluded that perineural dexmedetomidine reduces the onset time and prolongs the duration of sensory and motor block [4] [9] [10] Conversely, Gandhi R have demonstrated either a delay in sensory and motor block onset time [11] or no effect on sensory and motor block duration (24 Esmaoglu) [12] with the use of perineural dexmedetomidine. One possible explanation for this disagreement on sensory block onset is that they performed their surveys by using bupivacaine as the main local anesthetic; but we used lidocaine as our main local anesthetic, which may cause different effects on sensory block onset.

In the context of perineural adjuvants, [13] Candido KD concluded that the efficacy of dexmedetomidine appears to be comparable with buprenorphine when administered peripherally. However, dexmedetomidine is unlike clonidine, another $\alpha 2$ adrenoreceptor agonist shown capable of prolonging the duration of shorter acting [14] [15] but not long-acting Las. In our study, both dexmedetomidine and nalbuphine prolonged the sensory and motor blockade.

Different doses of perineural dexmedetomidine had been described. Doses varied between [12] $100 \mathrm{mg}$ [10], 0.75 [16], or $1 \mathrm{mic} / \mathrm{kg}$ [17]. These dosing inconsistencies most likely reflect the absence of human dose-response studies and/or extrapolation from animal studies [18]. Apparently, relevant neurotoxicity data seem contradictory; while a number of reports suggest that dexmedetomidine is protective against hypoxic - ischaemic neuronal injury in rat and human neonatal asphyxia models [19], dexmedetomidine has also been shown to cause moderate to severe demyelination in white matter when doses as high as $6.1 \mathrm{mic} / \mathrm{kg}$ were administered via an epidural route in rabbits [20]. While the doses used in the trials did not exceed $0.2 \mathrm{mic} / \mathrm{kg}$ for intrathecal and $1 \mathrm{mic} / \mathrm{kg}$ for peripheral administration, the hazards of drawing conclusions of safety based on isolated small animal data are self-evident [21].

In the context of IVRA Esmaoglu A, and Kol IO concluded that, in agreement with our findings, addition of dexmedetomidine to prilocaine in IVRA decreases pain scores, improves anesthesia quality, decreases analgesic requirement, shortens sensory block onset time, and prolongs sensory block recovery time [22] [23]. However Esmaoglu concluded that addition of dexmedetomidine to lidocaine has no effect on the sensory and motor block onset and regression time [22].

Using basic concepts of peripheral opioid activity, anesthesiologists have attempted to capitalize on the presence of peripheral opioid receptors to improve the quality of intraoperative and/or postoperative regional anesthesia [24]. The scientific basis for this theory was based on the presence of opioid receptors and their endogenous ligands in the peripheral nervous system, and their effect on modulation of inflammatory pain. However, recent systematic reviews have concluded that, opioids lack significant effect in this setting [24]. As outlined by Choyce and Peng [25] in a systemic review on IVRA adjuncts in 2002, results of early studies evaluating mor- 
phine, fentanyl, meperidine, sufentanil, and tramadol as adjuncts were disappointing. Since this time, however, new studies have continued to assess the benefits of several opioids, with a focus on sufentanil and tramadol, as well as the combination of opioids with muscle relaxants in an attempt to decrease the required dose of LA.

Tramadol has shown a faster onset of sensory block and improved tourniquet tolerance, but a lack of consistent postoperative benefits and an increased risk of minor side effects (such as localized skin rash) have been found [26]. A Puttappa concluded that the addition of fentanyl has shown excellent to good intraoperative analgesia even with low dose lignocaine. Addition of pancuronium to low dose lignocaine and fentanyl improved the quality of analgesia and relaxation in such a way that upper limb surgery could be accomplished with success in all cases [27]. Though there is a virtual absence of opiate receptors in the spinal ventral roots and in peripheral nerves [27], fentanyl is found to reduce the action potential in desheathed peripheral nervous system similar to that produced by LA. This action is not related to opiate receptors as naloxone failed to inhibit this effect, Therefore, it is possible that addition of fentanyl to lignocaine enhances the LA action of fentanyl and this synergism allows the reduction of dose of lignocaine in IVRA. The later conclusion agrees with our results as nalbuphine was superior to the other groups regarding the analgesic properties.

The peripheral analgesic effect of opioids is still controversial [27]. Although no in vivo studies have demonstrated a measurable local anaesthetic effect of fentanyl, in vitro studies have shown that perineural fentanyl depresses the action potential in nerve fibres of different types. Brown $\mathrm{E}$ et al. recorded the fast conducting A fibres and slow conducting $C$ fibres before and after exposure to 50 and $100 \mu \mathrm{g} / \mathrm{ml}$ of fentanyl and indicated that a high concentration of fentanyl may partially suppress conduction in peripheral nerve and apparently does not diffuse well through a nerve sheath [28]. Thus it is unlikely that fentanyl perse would cause conduction blockade in vivo in peripheral nerves that are enclosed within a nerve sheath.

Similarly, $\alpha 2$ adrenoreceptors are not present on the axon of the normal peripheral nerve. In one study, clonidine without LA given through an interscalene catheter provided better analgesia compared with the systemic administration of the same dose [29]. This suggests the peripheral action of $\alpha 2$ agonists.

There is a great similarity between nalbuphine and butorphanol regarding the chemical nature (synthetic mixed k-agonist- $\mu$-antagonists, mode of action on opioid receptors, and inhibition of serotonin neuronal uptake resulting in augmentation of the spinal inhibitory pathways for pain) [30]. Both are equianalgesic producing sedation and analgesia, with minimal side effects. However, the analgesic duration of nalbuphine is much longer than that of butorphanol, [30]. Unfortunately, nalbuphine was studied in detail as an adjuvant to local anesthetics in epidural and intrathecal anesthesia [31]. In agreement with our findings, Nasr and Waly [5] have studied the effect of tramadol addition to lidocaine as against dexmedetomidine addition to lidocaine in IVRA. They found that there was a statistically significant acceleration of both sensory and motor onsets in the tramadol and dexmedetomidine groups in comparison with the lidocaine group.

\section{Conclusion}

Nalbuphine is superior to dexmedetomidine as an additive to local anesthetic in IVRA regarding onset, duration of block and post operative analgesia.

\section{References}

[1] Brill, S., Middleton, W., Brill, G. and Fisher, A. (2004) Bier’s Block; 100 Years Old and Still Going Strong. Acta Anaesthesiologica Scandinavica, 48, 117-122. http://dx.doi.org/10.1111/j.1399-6576.2004.00280.x

[2] Candido, K.D. and Winnie, A.P. (2007) Intravenous Regional Block for Upper and Lower Extremity Surgery. In: Hadzic, A., Ed., Textbook of Regional Anesthesia and Acute Pain Management, 2nd Edition, McGraw-Hill Professional, New York, 565-578.

[3] Choyce, A. and Peng, P. (2002) A Systematic Review of Adjuncts for Intravenous Regional Anesthesia for Surgical Procedures. Canadian Journal of Anesthesia, 49, 32-45. http://dx.doi.org/10.1007/BF03020416

[4] Memiş, D., Turan, A., Karamanlioğlu, B., Pamukçu, Z. and Kurt, I. (2004) Adding Dexmedetomidine to Lidocaine for Intravenous Regional Anesthesia. Anesthesia \& Analgesia, 98, 835-840.

[5] Nasr, Y.M. and Waly, S.H. (2012) Lidocaine-Tramadol versus Lidocaine-Dexmedetomidine for Intravenous Regional Anesthesia. Egyptian Journal of Anaesthesia, 28, 37-42. http://dx.doi.org/10.1016/j.egja.2011.08.003

[6] Youssef, M.M.I. and ElZayyat NS (2014) Lidocaine-Nalbuphine versus Lidocaine-Tramadol for Intravenous Regional Anesthesia. Ain-Shams Journal of Anaesthesiology, 7,198-204. 
[7] Price, D.D., McGrath, P.A., Rafii, I.A. and Buckingham, B. (1983) The Validation of Visual Analogue Scales as Ratio Scale Measures for Chronic and Experimental Pain. Pain, 17, 45-56. http://dx.doi.org/10.1016/0304-3959(83)90126-4

[8] Ramsay, M.A., Savege, T.M., Simpson, B.R. and Goodwin, R. (1974) Controlled Sedation with Alphaxalone-Alphadolone. BMJ, 2, 656-659. http://dx.doi.org/10.1136/bmj.2.5920.656

[9] Esmaoglu, A., Yegenoglu, F., Akin, A. and Turk, C. (2010) Dexmedetomidine Added to Levobupivacaine Prolongs Axillary Brachial Plexus Block. Anesthesia \& Analgesia, 111, 1548-1151. http://dx.doi.org/10.1213/ane.0b013e3181fa3095

[10] Kanazi, G.E., Aouad, M.T., Jabbour Khoury, S.I., et al. (2006) Effect of Low-Dose Dexmedetomidine or Clonidine on the Characteristics of Bupivacaine Spinal Block. Acta Anaesthesiologica Scandinavica, 50, 222-227. http://dx.doi.org/10.1111/j.1399-6576.2006.00919.x

[11] Gandhi, R., Shah, A. and Patel, I. (2012) Use of Dexmedetomidine Along with Bupivacaine for Brachial Plexus Block. National Journal of Medical Research, 2, 67-69.

[12] Esmaoglu, A., Mizrak, A., Akin, A., Turk, Y. and Boyaci, A. (2005) Addition of Dexmedetomidine to Lidocaine for Intravenous Regional Anaesthesia. European Journal of Anaesthesiology, 22, 447-451. http://dx.doi.org/10.1017/S0265021505000761

[13] Candido, K.D. (2002) Buprenorphine Added to the Local Anesthetic for Axillary Brachial Plexus Block Prolongs Postoperative Analgesia. Regional Anesthesia and Pain Medicine, 27, 162-167. http://dx.doi.org/10.1097/00115550-200203000-00009

[14] Singelyn, F.J., Dangoisse, M., Bartholome, S. and Gouverneur, J.M. (1992) Adding Clonidine to Mepivacaine Prolongs the Duration of Anesthesia and Analgesia after Axillary Brachial Plexus Block. Regional Anesthesia and Pain Medicine, 17, 148-150.

[15] Culebras, X., Van Gessel, E., Hoffmeyer, P. and Gamulin, Z. (2001) Clonidine Combined with a Long Acting Local Anesthetic Does Not Prolong Postoperative Analgesia after Brachial Plexus Block but Does Induce Hemodynamic Changes. Anesthesia \& Analgesia, 92, 199-204. http://dx.doi.org/10.1097/00000539-200101000-00038

[16] Ammar, A.S. and Mahmoud, K.M. (2012) Ultrasound-Guided Single Injection Infraclavicular Brachial Plexus Block Using Bupivacaine Alone or Combined with Dexmedetomidine for Pain Control in Upper Limb Surgery: A Prospective Randomized Controlled Trial. Saudi Journal of Anaesthesia, 6, 109-114. http://dx.doi.org/10.4103/1658-354X.97021

[17] Kaygusuz, K. (2012) Effects of Adding Dexmedetomidine to Levobupivacaine in Axillary Brachial Plexus Block. Current Therapeutic Research, Clinical and Experimenta, 73, 103-111. http://dx.doi.org/10.1016/j.curtheres.2012.03.001

[18] Takano, Y. and Yaksh, T.L. (1992) Characterization of the Pharmacology of Intrathecally Administered Alpha-2 Agonists and Antagonists in Rats. Journal of Pharmacology and Experimental Therapeutics, 261, 764-772.

[19] Hoffman, W.E., Kochs, E., Werner, C., Thomas, C. and Albrecht, R.F. (1991) Dexmedetomidine Improves Neurologic Outcome from Incomplete Ischemia in the Rat. Reversal by the Alpha 2-Adrenergic Antagonist Atipamezole. Anesthesiology, 75, 328-332. http://dx.doi.org/10.1097/00000542-199108000-00022

[20] Konakci, S., Adanir, T., Yilmaz, G. and Rezanko, T. (2008) The Efficacy and Neurotoxicity of Dexmedetomidine Administered via the Epidural Route. European Journal of Anaesthesiology, 25, 403-409. http://dx.doi.org/10.1017/S0265021507003079

[21] Yaksh, T.L., Ilfeld, B.M. and Wiese, A.J. (2012) Perineural Local Anesthetic and Adjuvant Action: The Meaning of an ex Vivo Data Set for Efficacy and Safety. Regional Anesthesia \& Pain Medicine, 37, 366-368. http://dx.doi.org/10.1097/AAP.0b013e31825afa5b

[22] Esmaoglu, A., Mizrak, A., Akin, A., Turk, Y. and Boyaci, A. (2005) Addition of Dexmedetomidine to Lignocaine for Intravenous Regional Anesthesia. European Journal of Anaesthesiology, 22, 447-451. http://dx.doi.org/10.1017/S0265021505000761

[23] Kol. I.O., Ozturk, H., Kaygusuz, K., Gursoy, S., Comert, B. and Mimaroglu, C. (2009) Addition of Dexmedetomidine or Lornoxicam to Prilocaine in Intravenous Regional Anesthesia for Hand or Forearm Surgery: A Randomized Controlled Study. Clinical Drug Investigation, 29, 121-129. http://dx.doi.org/10.2165/0044011-200929020-00006

[24] Picard, P.R., Tramèr, M.R., McQuay, H.J. and Moore, R.A. (1997) Analgesic Efficacy of Peripheral Opioids (All Except Intra-Articular): A Qualitative Systematic Review of Randomised Controlled Trials. Pain, 72, 309-318. http://dx.doi.org/10.1016/S0304-3959(97)00040-7

[25] Choyce, A. and Peng, P. (2002) A Systematic Review of Adjuncts for Intravenous Regional Anesthesia for Surgical Procedures. Canadian Journal of Anesthesia, 49, 32-45. http://dx.doi.org/10.1007/BF03020416

[26] Kapral. S., Gollmann, G., Waltl, B., et al. (1999) Tramadol Added to Mepivacaine Prolongs the Duration of an Axillary Brachial Plexus Blockade. Anesthesia \& Analgesia, 88, 853-856. 
[27] Puttappa, A. and Patkar, G. (2009) Intravenous Regional Anaesthesia with Lignocaine, Fentanyl and PancuroniumProspective Randomised Controlled Double Blind Study. The Internet Journal of Anesthesiology, 24.

[28] Brown, E.M., McGriff, J.T. and Malinowski, R.W. (1989) Intravenous Regional Anaesthesia (Bier Block): Review of 20 Years' Experience. Canadian Journal of Anaesthesia, 36, 307-310. http://dx.doi.org/10.1007/bf03010770

[29] Iskandar, H., Benard, A., Ruel-Raymond, J., Cochard, G. and Manaud, B. (2003) The Analgesic Effect of Interscalene Block Using Clonidine as an Analgesic for Shoulder Arthroscopy. Anesthesia \& Analgesia, 96, 260-262.

[30] Youssef, M.M. and ElZayyat, N.S. (2014) Lidocaine-Nalbuphine versus Lidocaine-Tramadol for Intravenous Regional Anesthesia. Ain-Shams Journal of Anesthesiology, 7, 198-204. http://dx.doi.org/10.4103/1687-7934.133441

[31] Mukherjee, A., Pal, A., Agrawal, J., Mehrotra, M. and Dawar, N. (2011) Intrathecal Nalbuphine as an Adjuvant to Subarachnoid Block: What Is the Most Effective Dose? Anesthesia, 5, 171-175.

\section{Submit or recommend next manuscript to SCIRP and we will provide best service for you:}

Accepting pre-submission inquiries through Email, Facebook, Linkedin, Twitter, etc A wide selection of journals (inclusive of 9 subjects, more than 200 journals)

Providing a 24-hour high-quality service

User-friendly online submission system

Fair and swift peer-review system

Efficient typesetting and proofreading procedure

Display of the result of downloads and visits, as well as the number of cited articles

Maximum dissemination of your research work

Submit your manuscript at: http://papersubmission.scirp.org/ 